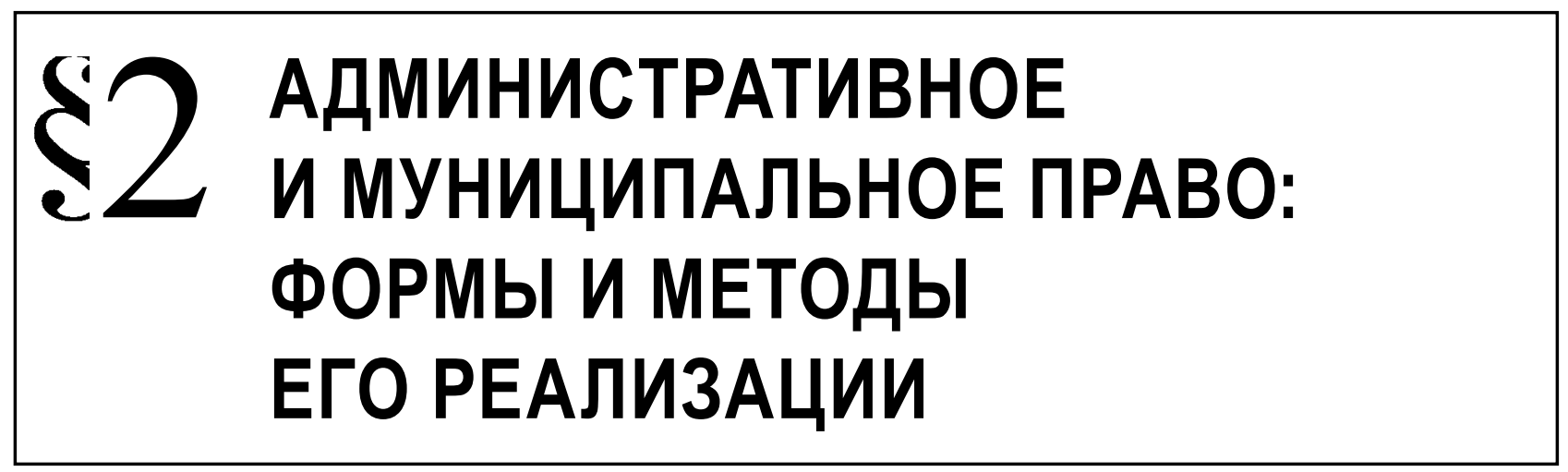

Трофримчук Н.B.

\title{
НЕКОТОРЫЕ ПРОБЛЕМЫ ИНСТИТУТА КОНТРОЛЯ (НАДЗОРА) ПРЕДПРИНИМАТЕЛЬСКОЙ ДЕЯТЕЛЬНОСТИ ПО ЗАКОНОДАТЕЛЬСТВУ РОССИЙСКОЙ ФЕДЕРАЦИИ
}

Аннотация. Предметом статьи являются проблемы правового и правоприменительного характера при осуществлении государственного контроля (надзора) и муниципального контроля предпринимательской деятельности. Автором проводится анализ правового регулирования исследуемой сферы общественных отношений, его значение и эффрективность. Основное внимание в статье уделяется проблеме унификации процедуры государственного контроля (надзора), муниципального контроля и роли Федерального закона «О защите прав юридических лиц и индивидуальных предпринимателей при осуществлении государственного контроля (надзора) и муниципального контроля» в реализации этой задачи.Кроме того, в статье проводится теоретико-правовой анализ понятий "взаимодействие" контрольно-надзорных органов и юридических лии, индивидуальных предпринимателей, а также "манипулирование рынком". В статье представлены авторские позиции относительно толкования данных категорий. Методологическую основу статьи составили современные достижения теории познания. В процессе исследования применялись теоретический, общефилософские методы (диалектика, системный метод, анализ, синтез, аналогия, дедукция, наблюдение, моделирование), традиционно правовые методы (формально-логический). Основной вывод, который сделан по итогам исследования, состоит в том, что в настоящее время не срормирована единая правовая основа деятельности контрольно-надзорных органов, нет системообразующего вектора ее развития. Основным вкладом, который сделан автором в настоящей статье является разработка предложений по совершенствованию правового регулирования исследуемых правоотношений. Новизна статьи заключается в разработке предложений о необходимости включения в текст Федерального закона «О защите прав юридических лиц и индивидуальных предпринимателей при осуществлении государственного контроля (надзора) и муниципального контроля» процедуры досудебного обжалования решений, действий (бездействия) контрольно-надзорных органов, с учетом особенностей этой стороны деятельности государственных и муниципальных органов. В статье также представлена авторская позиция относительно толкования понятий "взаимодействие" контрольно-надзорных органов и юридических лиц, индивидуальных предпринимателей и "манипулирование рынком".

Ключевые слова: государственный контроль (надзор), предприниматель, хозяйствующий субъект, законодательство, правовое регулирование, муниципальный контроль, юридическое лицо, федеральный закон, защита прав, обязанность.

Abstract. The research subject is the range of legal and law enforcement problems of government control (supervision) and municipal control over entrepreneurial activities. The author analyzes legal regulation of this sphere of social relations, its importance and effectiveness. The main attention is paid to the problem of unification of the procedure of government control (supervision), municipal control and the role of the Federal Law "On the protection of rights of legal entities and self-employed persons upon the realization of government and municipal control (supervision)". Besides, the author carries out theoretical and legal analysis of the concepts of "interaction" of supervisory bodies, legal entities and self-employed persons and "market manipulation". The article demonstrates the author's positions on the interpretation of these categories. The research methodology comprises the modern achievements in epistemology. The author applies theoretical and general philosophical methods (dialectics, the system method, analysis, synthesis, 
analogy, deduction, observation, modeling) and traditional legal methods (formal logical). The author concludes that at present there is no uniform legal basis for the activities of supervisory bodies, and there is no framework vector of its development. The main contribution of the author is the proposals about the improvement of legal regulation of the relations under consideration. The novelty of the study consists in the proposals about amending the text of the Federal Law "On the protection of rights of legal entities and self-employed persons upon the realization of government and municipal control (supervision)" with the procedure of pre-trial appeal of decisions, actions (inactions) of supervisory bodies with account for the particularities of this form of activity of public and municipal authorities. The article demonstrates the author's position on the interpretation of the concepts of "interaction" of supervisory bodies, legal entities and self-employed persons and "market manipulation".

Key words: legal regulation, municipal control, legal entity, federal law, protection of rights, responsibility, legislation, business entity, self-employed person, public control (supervision).

$\Pi$ равовое регулирование предпринимательской деятельности на современном этапе своего развития не имеет системообразующего вектора. По этой причине институт государственного контроля (надзора) предпринимательской деятельности представляет собой сложную и постоянно меняющуюся систему норм, регламентов, правил. Принимаемые нормативные акты зачастую сложны в применении, содержат обширное специальное регулирование и большое количество бланкетных норм, отсылающих к подзаконным нормативным правовым актам.

Принятый в 2008 г. Федеральный закон «0 защите прав юридических лиц и индивидуальных предпринимателей при осуществлении государственного контроля (надзора) и муниципального контроля» [1] (далее ФЗ о контроле (надзоре)) не решил в полной мере проблему упорядочения взаимоотношений государства и предпринимательства в рассматриваемой сфере общественных отношений.

Сформулированные еще в 2008 году Концепцией долгосрочного социально-экономического развития Российской Федерации на период до 2020 года [2] основные направления развития системы контроля и надзора не потеряли своей актуальности и сегодня. В своем послании Федеральному Собранию на 2016 г. [3] Президент Российской Федерации указал на необходимость сокращения административных ограничений предпринимательской деятельности, обеспечение эффективной регламентации полномочий органов по контролю (надзору) и повышение гарантий защиты прав юридических лиц и индивидуальных предпринимателей при проведении государственного контроля (надзора), «..прошу Правительственную комиссию по административной реформе совместно с деловыми объединениями представить до 1 июля 2016 года конкретные предложения по устранению избыточных и дублирующих функций контрольно-надзорных органов...». Президент также отметил недостаточную эффективность контрольной и надзорной деятельности органов исполнительной власти и их должностных лиц.

Поэтому очень важным представляется исследование законодательства в данной области правоотношений.

Федеральным законом о контроле (надзоре) определяется понятие государственного контроля. Это деятельность уполномоченных органов государственной власти, направленная на предупреждение, выявление и пресечение нарушений юридическими лицами, индивидуальными предпринимателями (далее хозяйствующие субъекты) требований, установленных Федеральным законом о контроле (надзоре), другими федеральными законами и принимаемыми в соответствии с ними иными нормативными правовыми актами Российской Федерации, законами и иными нормативными правовыми актами субъектов Российской Федерации (далее - обязательные требования), посредством организации и проведения проверок, принятия мер по пресечению и (или) устранению последствий выявленных нарушений, а также деятельность по систематическому наблюдению за исполнением обязательных требований, анализу и прогнозированию состояния исполнения обязательных требований хозяйствующими субъектами [1, ст. 2].

Закон о контроле (надзоре) также проводит разграничение федерального, регионального и муниципального контроля [1, ст. 2].

Следует сказать, что цель унифицировать процедуру государственного контроля (надзора), с принятием ФЗ о контроле (надзоре), достичь не удалось. Из сферы его действия исключены отдельные виды государственного контроля (надзора) [1, ст. 3, 3.1], в частности, при проведении оперативно-розыскных мероприятий, при производстве дознания, при проведении предварительного следствия; при осуществлении прокурорского надзора (за исключением случаев проведения органами государственного контроля (надзора)); при производстве по делам о нарушении антимонопольного законодательства Российской Федерации; при рас- 


\section{Административное и муниципальное право 6 (102) • 2016}

следовании причин возникновения чрезвычайных ситуаций природного и техногенного характера и ликвидации их последствий и др.

В целом на данном этапе развития, законодательство о государственном контроле (надзоре) в сфере предпринимательской деятельности представляет собой общие и специальные нормы. К общим можно отнести ФЗ о контроле (надзоре), который регулирует вопросы:

1) организации и проведения проверок юридических лиц, индивидуальных предпринимателей органами, уполномоченными на осуществление государственного контроля (надзора), муниципального контроля;

2) взаимодействия органов, уполномоченных на осуществление государственного контроля (надзора), муниципального контроля, при организации и проведении проверок;

3) устанавливает права и обязанности органов, уполномоченных на осуществление государственного контроля (надзора), муниципального контроля, их должностных лиц при проведении проверок;

4) устанавливает права и обязанности юридических лиц, индивидуальных предпринимателей при осуществлении государственного контроля (надзора), муниципального контроля, меры по защите их прав и законных интересов.

Как ранее отмечалось, ФЗ о контроле (надзоре) упускает из правового поля своего воздействия некоторые вопросы, что затрудняет практическое применение его норм.

Так, дискуссионным является вопрос относительно конституционности положений ФЗ о контроле (надзоре) и ряда других нормативных правовых актов РФ, устанавливающих обязанность хозяйствующих субъектов предоставлять по запросам контролирующих органов необходимые документы [1, ст. 11]. Дискуссия состоит в конкуренции интересов, когда, реализуя свои законные полномочия, контрольно-надзорные органы имеют обеспеченную законом возможность, не учитывать конституционные права граждан. Пожалуй, стоит согласиться с точкой зрения, согласно которой формулировки п. 5 ст. 11 ФЗ о контроле (надзоре), прямо указывающие на обязанность хозяйствующих субъектов выполнить указанные действия, под страхом юридической ответственности (например, ст. 17.7.2 КоАП РФ), нарушают их конституционные права [4]. Таким образом, считаем, что невозможность отказаться юридическому лицу, индивидуальному предпринимателю от предоставления документов по запросу контролирующего органа, представляет собой нарушение конституционного права не свидетельствовать против самого себя и своих близких, и предлагаем вышеуказанные нормативные правовые акты привести в соответствие с Конституцией РФ.

Так же ФЗ о контроле (надзоре) не предусмотрен порядок досудебного обжалования решений, действий (бездействия) контрольно-надзорных органов. Ст. 23 ФЗ о контроле (надзоре) лишь указывает на возможность юридических лиц и индивидуальных предпринимателей реализовать свое право на защиту при осуществлении государственного контроля (надзора), муниципального контроля, в административном и (или) судебном. Существующий Федеральный закон от 2 мая 2006 г. № 59-Ф3 «0 порядке рассмотрения обращений граждан Российской Федерации» [5] устанавливает общий порядок рассмотрения жалоб граждан в порядке досудебного урегулирования споров. Справедливые возражения относительно излишнего дублирования норм в различных нормативных правовых актах в данном случае вступает, на наш взгляд, в противоречие с концептуальным пониманием осуществления государственного контроля (надзора) в сфере предпринимательской деятельности. Последнее предполагает формирования единой правовой основы деятельности контрольно-надзорных органов. Таким образом, представляется необходимым внести в ФЗ о контроле (надзоре) положения, определяющие особенности, а также процедуру досудебного обжалования решений, действий (бездействия) контрольно-надзорных органов.

Ряд формулировок ФЗ о контроле (надзоре) не однозначны в своем понимании, что вызывает определенные трудности в применении на практике [6]. Например, п.3 ст. 1 ФЗ о контроле (надзоре) устанавливает пределы действия указанного федерального закона, когда его положения не применяются, в частности, если при проведении мероприятий по контролю не требуется взаимодействие контрольно-надзорных органов и юридических лиц, индивидуальных предпринимателей. Представляется необходимым конкретизировать термин «взаимодействие», в целях устранения ошибочного применения положений указанного федерального закона. Вероятно, под «взаимодействием» законодатель понимает правоотношение между хозяйствующим субъектом и контролирующим органом, возникшее в ходе реализации последним своих полномочий.

В ст. 1 п. 3 ФЗ о контроле (надзоре) используется понятие «манипулирование рынком», в тоже время его значение не раскрывается. Федеральный закон от 27 июля 2010 г. № 224-ФЗ «0 противодействии неправомерному использованию инсайдерской информации и манипулированию рынком» [7] перечисляет действия, которые подпадают под данное определение, что тем не менее, 
не дает полного представления о сущности такого противоправного деяния, как «манипулирование рынком». Из содержания ст. 1, ст. 5, Федерального закона от 27 июля 2010 г. № 224-Ф3 «0 противодействии неправомерному использованию инсайдерской информации и манипулированию рынком» можно предложить следующее определение понятия «манипулирование рынком» - это любые действия («..умышленное распространение через средства массовой информации сведений, совершение операций, совершение сделок, выставление заявок ..»), и/или бездействие («..неоднократное неисполнение обязательств по операциям..), препятствующие справедливому ценообразованию на финансовые инструменты, иностранную валюту и (или) товары, нарушающие равенство инвесторов и которые могут повлечь или повлекли формирование и/или поддержание несправедливого уровня организованных торгов.

Предвосхищая возможные апелляции к ст. 185.3 УК РФ по данному вопросу, следует сказать, что данный состав преступления определяет «манипулирование рынком» как действие. Вместе с тем, ст. 5 Федерального закона «0 противодействии неправомерному использованию инсайдерской информации и манипулированию рынком» рассматривает «манипулирование рынком» и как бездействие. Таким образом, по своему содержанию представленное автором определение в полной мере соответствует смыслу того понятия «манипулирование рынком», который вкладывает в него федеральный закон.

Вышеизложенное позволяет сформулировать ряд заключительных положений:

институт государственного контроля (надзора) предпринимательской деятельности представляет собой сложную и постоянно меняющуюся систему норм, регламентов, правил. На сегодняшний день эта система недостаточно эффективна выполняет свои функции. Современные тенденции в части создания нового законодательства в области государственного контроля (надзора) и муниципального контроля видятся в сокращении административных ограничений предпринимательской деятельности, обеспечении эффективной регламентации полномочий органов по контролю (надзору) и повышение гарантий защиты прав юриди- ческих лиц и индивидуальных предпринимателей при проведении государственного контроля (надзора) и муниципального контроля.

Исследование уже имеющегося законодательства в данной области правоотношений, показало, что существующие нормы упускают из правового поля ряд вопросов, нерешенность которых затрудняет его практическое применение.

В частности, считаем, что невозможность отказаться юридическому лицу, индивидуальному предпринимателю от предоставления документов по запросу контролирующего органа, представляет собой нарушение конституционного права не свидетельствовать против самого себя и своих близких, и предлагаем вышеуказанные нормативные правовые акты привести в соответствие с Конституцией РФ.

Представляется необходимым внести в ФЗ о контроле (надзоре) положения, определяющие особенности, а также процедуру досудебного обжалования решений, действий (бездействия) контрольно-надзорных органов.

Представляется необходимым конкретизировать термин «взаимодействие» контрольно-надзорных органов и юридических лиц, индивидуальных предпринимателей. Под «взаимодействием» предлагаем понимать правоотношение между хозяйствующим субъектом и контролирующим органом, возникшее в ходе реализации последним своих полномочий.

Из содержания ст. 1, ст. 5, Федерального закона «О противодействии неправомерному использованию инсайдерской информации и манипулированию рынком» автор предлагает следующее определение понятия «манипулирование рынком» - это любые действия («..умышленное распространение через средства массовой информации сведений, совершение операций, совершение сделок, выставление заявок ..»), и/ или бездействие («..неоднократное неисполнение обязательств по операциям..), препятствующие справедливому ценообразованию на финансовые инструменты, иностранную валюту и (или) товары, нарушающие равенство инвесторов и которые могут повлечь или повлекли формирование и/или поддержание несправедливого уровня организованных торгов.

\section{Библиография:}

1. Федеральный закон от 26 декабря 2008 г. № 295-Ф3 «0 защите прав юридических лиц и индивидуальных предпринимателей при осуществлении государственного контроля (надзора) и муниципального контроля» // Собрание законодательства РФ. 2008. № 52 (ч. І). Ст. 6249.

2. Распоряжение Правительства РФ от 17 ноября 2008 г. №1662-р // Собрание законодательства РФ. 2008. №47. Ст. 5489.

3. Послание Президента РФ Федеральному Собранию РФ от 03.12.2015 // Российская газета. 2015.04 декабря. №275. 


\section{Административное и муниципальное право 6 (102) • 2016}

4. Мицкевич Л.А., Васильева А.Ф. Современное состояние института государственного контроля (надзора) в сфере предпринимательской деятельности // Государство и право. 2015. № 10. С. 41-42.

5. Собрание законодательства РФ. 2006. № 19. Ст. 2060.

6. Постановление Третьего арбитражного апелляционного суда от 27 января 2012 г. по делу № A33-14638/2011; Постановление Четырнадцатого арбитражного апелляционного суда от 10 сентября 2012 г. по делу № А1316894/2011; Постановление Первого арбитражного апелляционного суда от 11 октября 2013 г. по делу № А439885/2013.

7. Собрание законодательства Российской Федерации. 2010 г. № 31 Ст. 4193.

8. Спектор А.А. К вопросу о видах и формах проверок при осуществлении государственного контроля (надзора) и муниципального контроля предпринимательской деятельности // Политика и Общество. 2011. № 12. С. 58-65.

\section{References (transliterated):}

1. Federal'nyi zakon ot 26 dekabrya 2008 g. № 295-FZ «O zashchite pravyuridicheskikh lits i individual'nykh predprinimatelei pri osushchestvlenii gosudarstvennogo kontrolya (nadzora) i munitsipal'nogo kontrolya» // Sobranie zakonodatel'stva RF. 2008. № 52 (ch. I). St. 6249.

2. Rasporyazhenie Pravitel'stva RF ot 17 noyabrya 2008 g. №1662-r // Cobranie zakonodatel'stva RF. 2008. №47. St. 5489.

3. Poslanie Prezidenta RF Federal'nomu Sobraniyu RF ot 03.12.2015 // Rossiiskaya gazeta. 2015. 04 dekabrya. №275.

4. Mitskevich L.A., Vasil'eva A.F. Sovremennoe sostoyanie instituta gosudarstvennogo kontrolya (nadzora) v sfere predprinimatel'skoi deyatel'nosti // Gosudarstvo i pravo. 2015. № 10. S. 41-42.

5. Sobranie zakonodatel'stva RF. 2006. № 19. St. 2060.

6. Postanovlenie Tret'ego arbitrazhnogo apellyatsionnogo suda ot 27 yanvarya 2012 g. po delu № A33-14638/2011; Postanovlenie Chetyrnadtsatogo arbitrazhnogo apellyatsionnogo suda ot 10 sentyabrya 2012 g. po delu № A1316894/2011; Postanovlenie Pervogo arbitrazhnogo apellyatsionnogo suda ot 11 oktyabrya 2013 g. po delu № A43$9885 / 2013$

7. Sobranie zakonodatel'stva Rossiiskoi Federatsii. 2010 g. № 31 St. 4193.

8. Spektor A.A. K voprosu o vidakh i formakh proverok pri osushchestvlenii gosudarstvennogo kontrolya (nadzora) i munitsipal'nogo kontrolya predprinimatel'skoi deyatel'nosti // Politika i Obshchestvo. 2011. № 12. C. 58-65. 